\title{
Papillary Cystadenoma of Larynx: A Case Report
}

\author{
Tammam Abou Ali ${ }^{1}$, Basel Al Sabah ${ }^{2}$, Kavitha Gopalan ${ }^{2}$ \\ ${ }^{1}$ Department of ENT, Farwaniya Hospital, Al-Farwaniyah, Kuwait \\ ${ }^{2}$ Department of ENT, Zain \& Al Sabah Hospital, Kuwait City, Kuwait \\ Email: kavient_raj@yahoo.com
}

Received August 28, 2013; revised September 26, 2013; accepted October 15, 2013

Copyright (C) 2013 Tammam Abou Ali et al. This is an open access article distributed under the Creative Commons Attribution License, which permits unrestricted use, distribution, and reproduction in any medium, provided the original work is properly cited.

\begin{abstract}
An uncommon clinical entity of papillary cystadenoma of the larynx in a lady of 37-year-old is presented. The diagnosis after clinical examination was achieved by video-stroboscopy, CT scan of the neck, biopsy and histopathological examination. This case study emphasizes the importance of recognition of this lesion by the clinician as the differential diagnosis includes lesions with similar clinical appearance.
\end{abstract}

Keywords: Papillary Cystadenoma; Larynx; Minor Salivary Gland Tumors

\section{Introduction}

Cyst adenomas represent between $2.0 \%$ and $4.7 \%$ of all minor salivary gland neoplasms [1,2], and papillary cystadenoma of salivary glands is an uncommon benign, well-circumscribed epithelial neoplasm resembling a mucous retention cyst. The median age of occurrence is 53.5 and 55 years [1] with a female prevalence. The cystic lesions have papillary projections arising from undifferentiated epithelium of the intercalated ducts of the glands [3] which could be the minor salivary glands, the parotid glands, oral cavity, larynx, nasopharynx or the lacrimal gland.

We herein present a case of multiple papillary cyst adenomas of the larynx with gross, histological features and important differential diagnosis of these lesions.

\section{Case Report}

A 37-year-old woman with unremarkable medical history, presented with dysphonia and mild dysphagia for liquids since one year which were gradually progressive. She did not give history of dyspnea, odynophagia, otalgia or cough. Laryngeal examination and videostroboscopy revealed multiple pinkish sessile cystic lesions of 1 to 1.5 $\mathrm{cm}$ diameter, with normal overlying mucosa, distributed all over the supraglottis giving a cobble-stone appearance. The true vocal folds were normal in appearance and mobility. The sub glottis was free. No cervical lymphadenopathy was noted. Serum biochemistry, full blood count and erythrocyte sedimentation rate were within normal limits. Computed tomography scan of neck revealed mild nodular irregularity of entire supraglottis including both false vocal cords (more appreciated on the left side) with normal CT appearance of true vocal cords as shown in Figure 1. Stroboscopy confirmed the CT findings of multiple cystic lesions in supraglottis as shown in Figures 2(a)-(c). Direct laryngoscopy and biopsy of the cystic lesions were done. Figures 3(a) and (b) show the cystic lesions in supraglottis while biopsied.

Histopathological analysis revealed benign tumors (cysts), covered my non-ulcerated mucosa of nonkeratinized squamous epithelium with areas of focal hy-

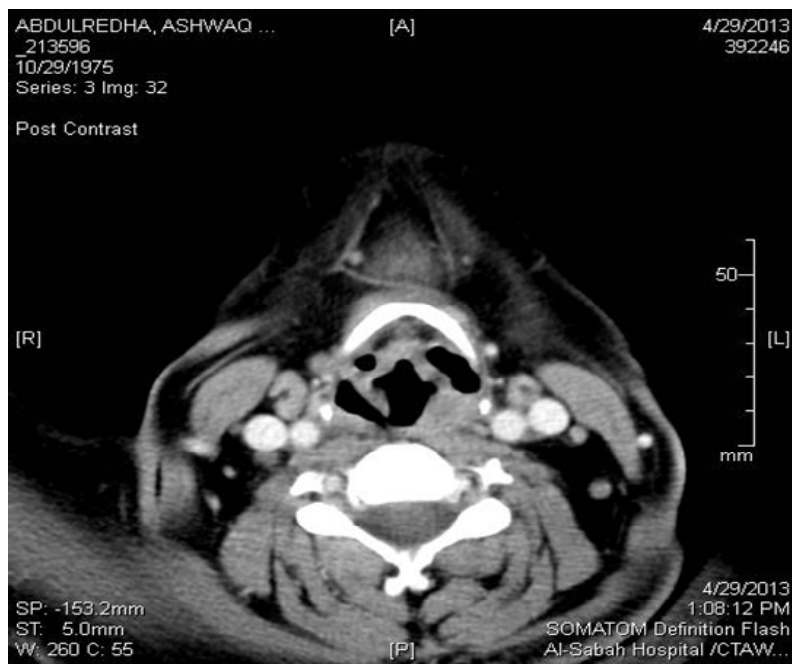

Figure 1. CT neck. 


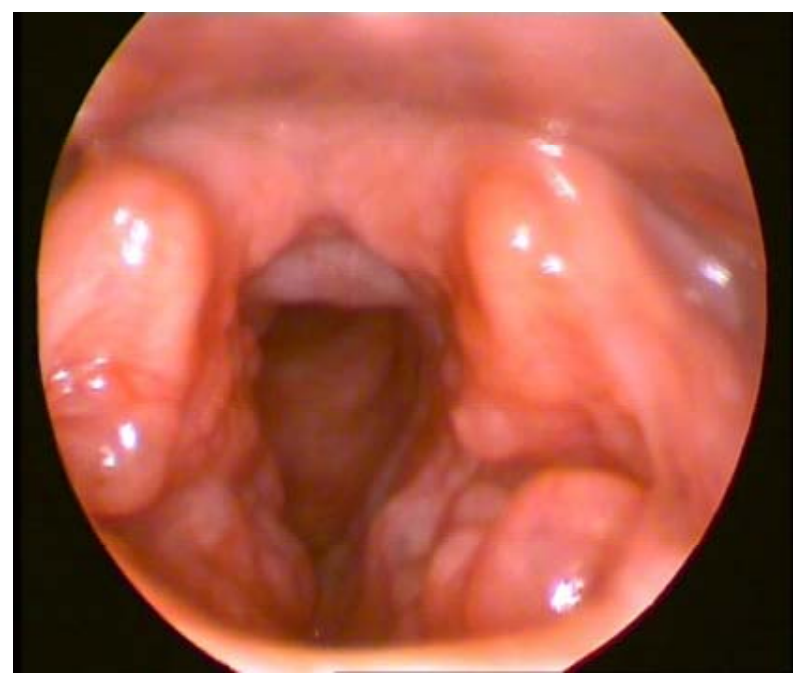

(a)

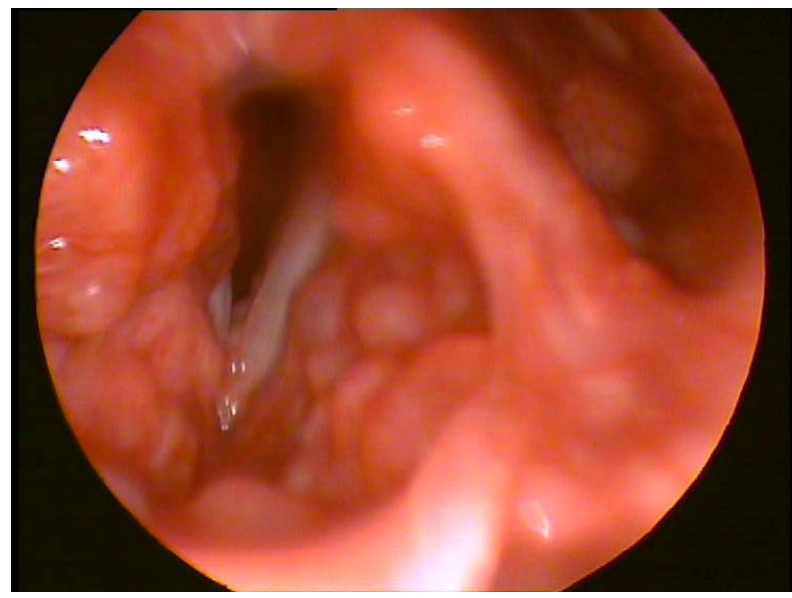

(b)

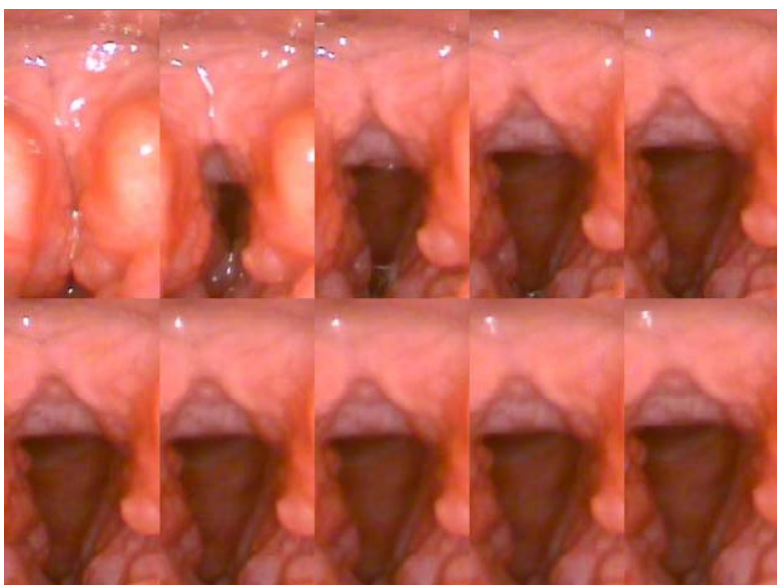

(c)

Figure 2. Stroboscopic pictures of larynx with multiple cystic lesions in the entire supraglottis.

perplasia as shown in Figures 4(a)-(c). Submucosa showed prominent fibrosis and mild inflammatory cellular infiltrate. The sub epithelial stroma showed multiple

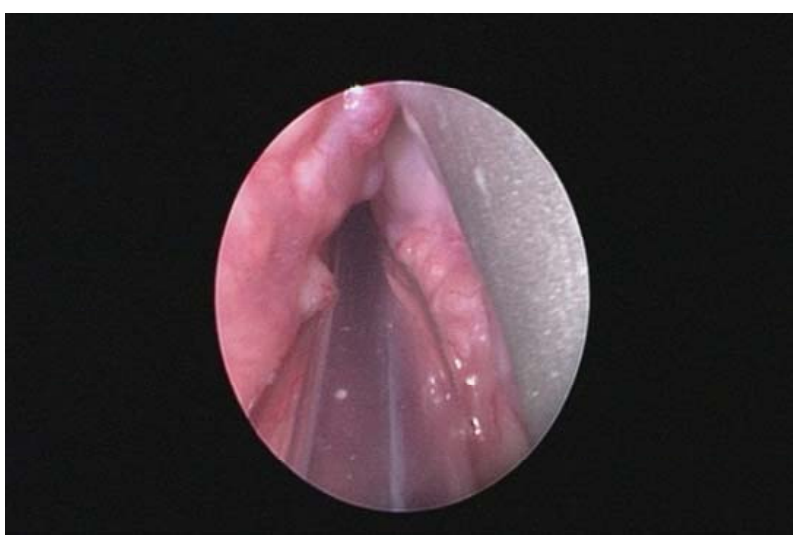

(a)

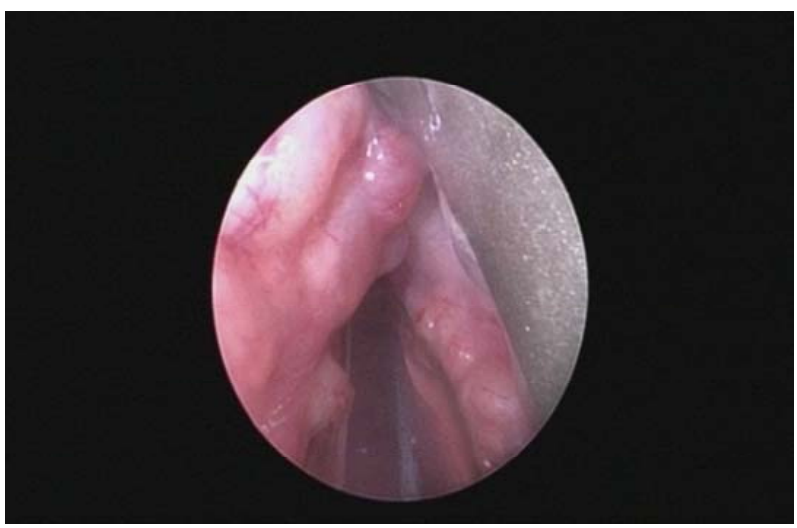

(b)

Figure 3. Operative pictures of the supraglottic cysts during biopsy.

cystic and partially solid nodules. The cystic cavity exhibited papillary growth and finger like processes with fibro vascular core as seen in Figures 5(a)-(c). The lining epithelium is mainly columnar with abundant cytoplasm and basophilic nucleus. No evidence of mitosis noted and no evidence of invasion to the surrounding connective tissue stroma was noted. The established diagnosis was papillary cystadenoma.

By endolaryngeal surgery using Kleinsasser's micro laryngoscopy technique, multiple cysts in entire supraglottis and false vocal cords were completely excised using micro instruments as shown in Figure 6. Laser or powered instruments were avoided for fear of fibrosis latter. Patient had uneventful post-operative recovery. Histopathology of the excised lesions confirmed the diagnosis of papillary cyst adenoma and no stromal invasion were identified.

The patient is currently being followed up and shows no signs of recurrence.

\section{Discussion}

The classification of salivary gland tumors by WHO (1991) has distinguished two variants of cystadenoma: 


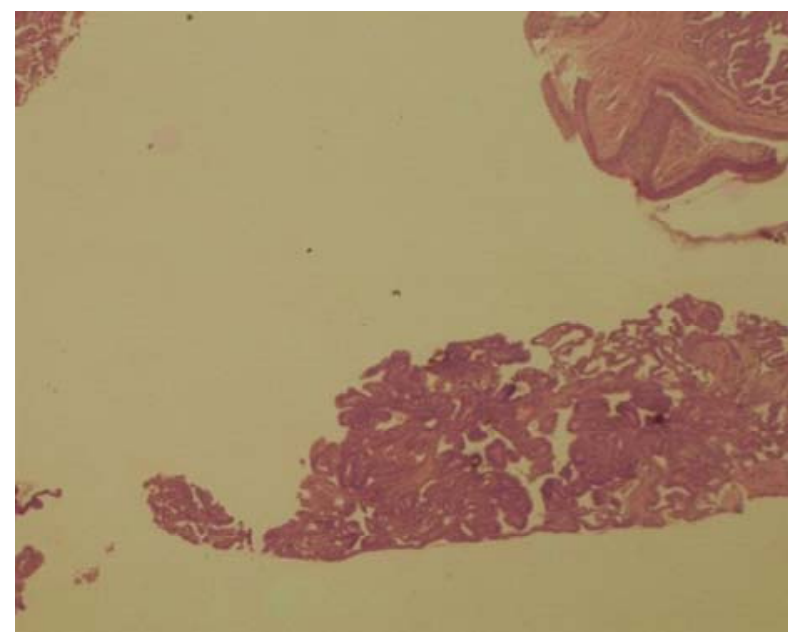

(a)

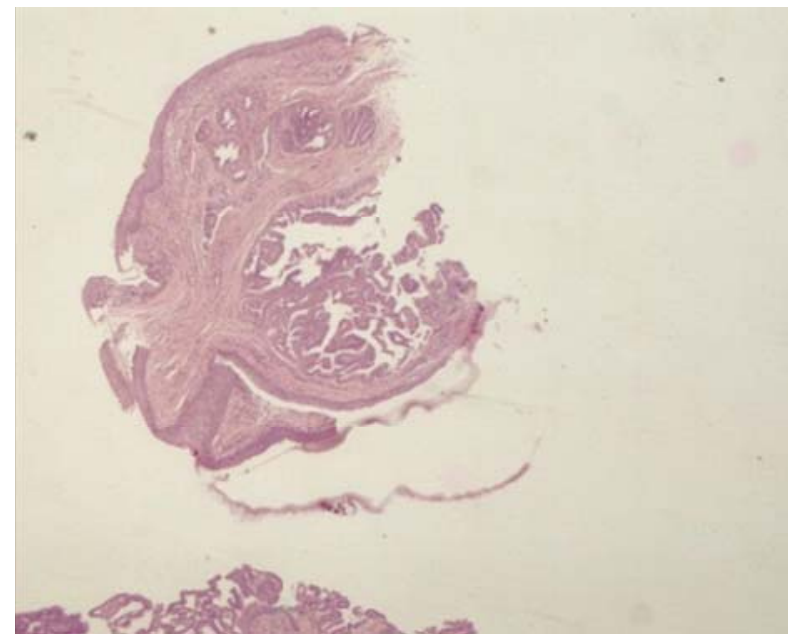

(b)
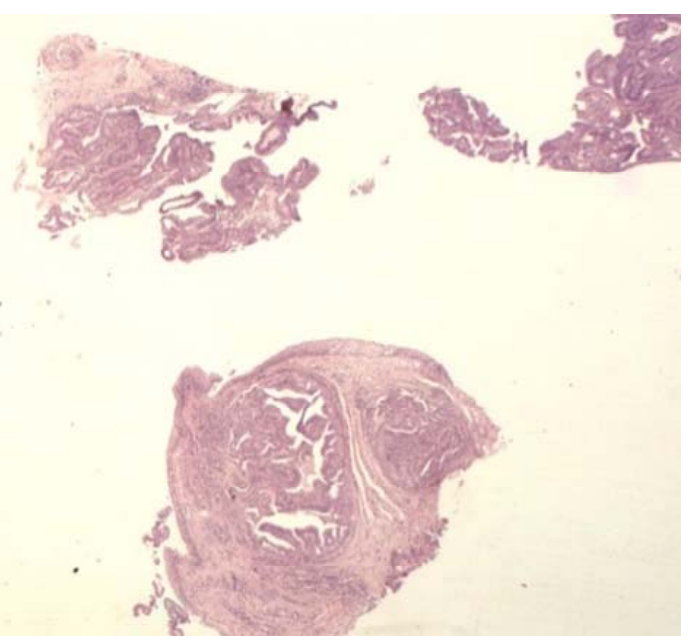

(c)

Figure 4. (a), (b) and (c) (LP): shows pieces of mucosa and sub mucosa, covered by non-keratinized squamous epithelium with no ulceration of the covering mucosa.

papillary cystadenoma and mucinous cystadenoma [4].

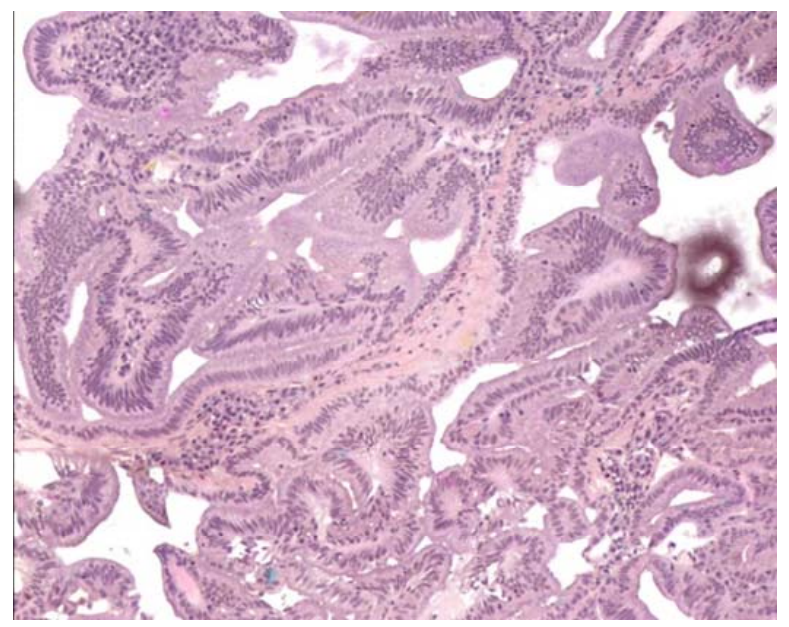

(a)

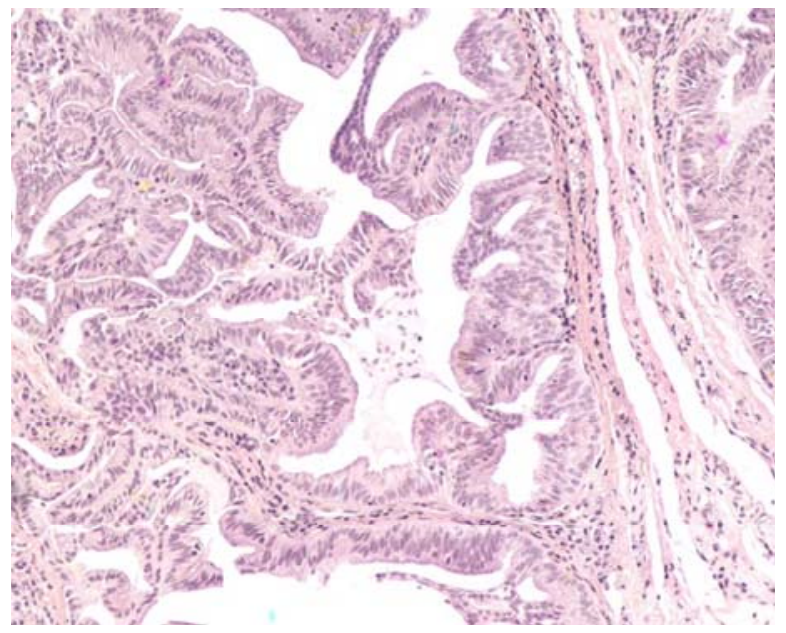

(b)

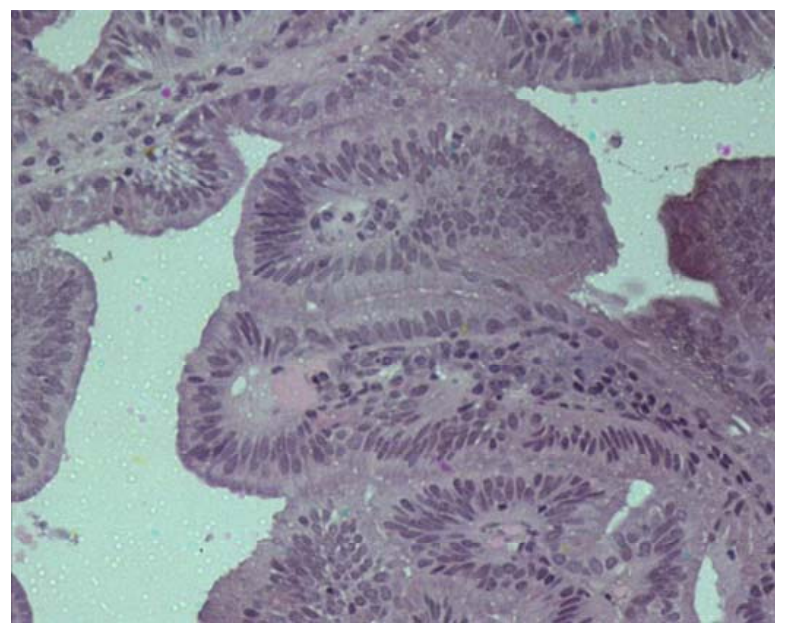

(c)

Figure 5. (a) and (b) $(H \& E \times 100)$ : cystic cavity exhibiting papillary projections supported by fibrous connective tissue; (c) $(H \& E \times 200)$ : papillary projections lined by tall columnar cells and surrounding tissue free of invasion.

Histologically, it consists of a multilocular proliferation 


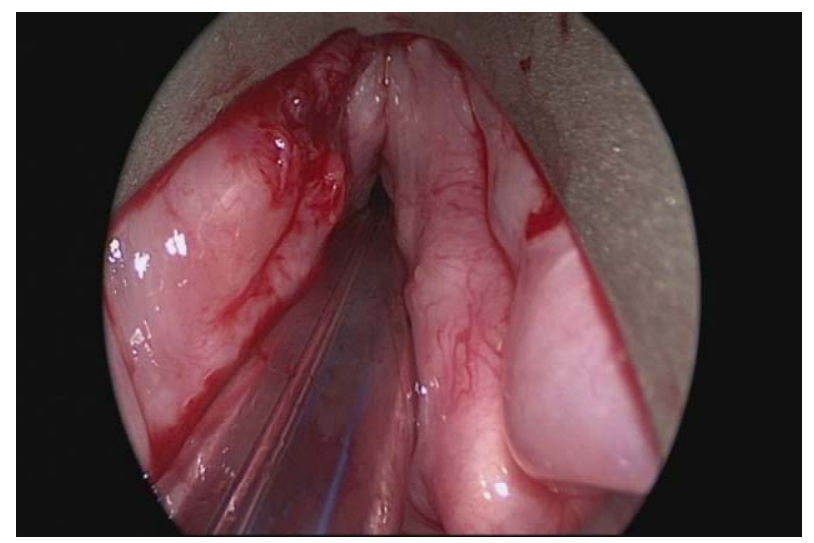

Figure 6. Operative picture of endoscopic excision of the lesions in the supraglottis.

of glandular epithelium. Epithelial cells may be columnar, cuboidal, squamous or oncocytic-like. Papillary formations are frequently seen. Stroma is fibrous, rarely with prominent lymphocytic elements. Papillary cystadenoma closely resembles Warthin's tumour, but is devoid of lymphoid stroma. Mucinous cystadenoma, like papillary cystadenoma, is a multicystictumour, but is lined by mucous-producing goblet cells. There are no atypia, nor any invasion, in either of the two types of cystadenoma. Papillary cystadenoma, although rare in salivary glands outside the larynx, can only occasionally be found in major salivary glands, the nasopharynx, buccal mucosa, the lacrimal gland the palate and the tonsillar region. Laryngeal papillary cystadenoma often show oncocytic metaplasia and are reactive cystic lesions with hyperplasia rather than true neoplasia [5]. This cellular oncocytosis appears to be age related and is accelerated by smoking.

The rarity of this tumour is reported by many authors. The incidence of papillary cystadenoma in a review of 426 cases of intraoral minor salivary gland tumours by Waldron et al. [6] is $4.7 \%$ of all minor salivary gland neoplasms and $8.1 \%$ of all benign epithelial minor salivary gland neoplasms. Similarly, Chaudry et al. [7] reported only $2 \%$ of occurrence of papillary cystadenoma in a large study of 800 intraoral minor salivary gland benign tumours.

Previous reports have shown an age range from 12 to 89 years, and an average age at diagnosis of 57 years [8]. Also, previous series have shown a female predominance $[7,9]$.

In our case, laryngeal examination along with videostroboscopy and CT scan of neck guided the clinical diagnosis of multiple cystic lesions in the supraglottis. Excision biopsy and histopathology ascribed the definite diagnosis of papillary cystadenoma. As special stains and immunohisto chemistry are non-contributory for the diagnosis [14], they were not done.
The histologic features of this case of papillary cystadenoma were characteristic of the lesion rendering the diagnosis easier. The lesions were well circumscribed having cystic spaces with intracystic papillary projections lined by tall columnar cells with basophilic nucleus. Oncocytes, squamous epithelium or mucous cells were not seen in these lesions which are common variants reported. No cellular atypia or mitotic figures were noted and adjacent stroma was free of invasion ruling out malignancy.

Clinically, the differential diagnosis encountering cystic lesions of the larynx includes mucous retention cysts, extra nodal lymphomas, lipomas, papillomas, schwannomas and neurofibromas, adenomatoid hyperplasia of minor salivary glands etc.

The important histological differential diagnosis of papillary cystadenoma includes papillary cystadenoma lymphomatosum, oncocytic cyst adenomas, oncocytomas, low-grade mucoepidermoid carcinoma, the papillarycystic variant of acinic cell carcinoma and cystadenocarcinoma [10].

Both papillary cystadenoma and papillary cystadenoma lymphomatosum (Warthin's tumour) are cystic tumors but are differentiated by the presence of numerous oncocytes, papillary formations and lymphoid stroma with lymph follicles which represent the main features of Warthin'stumour [1]. Oncocytic variants of papillary cystadenoma exist which could be confused with Warthin's tumour or oncocytoma.

Oncocytic cystadenoma is characterized by a smooth cyst wall composed of eosinophyllic cells with granular cytoplasm (due to numerous mitochondria). The cyst is adjacent to normal respiratory epithelium.

Oncocytomas are true adenomas and are composed of solid Oncocytes without cystic component.

Mucoepidermoid carcinoma is characterized histologically by solid nests composed of a mixture of mucous forming cells, epidermoid cells and sometimes of intermediate cells which are absent in cystadenoma.

In general, four different cell types constitute acinic cell carcinoma which includes large acinic cells, vacuolated cells, clear cells and non-specific glandular cells and in the papillary cystic variant of acinic cell carcinoma, a configuration with papillae in cystic spaces is seen which resembles papillary cystadenoma [11]. A microcystic growth pattern in the intra luminar fronds which is a characteristic feature of acinic cell carcinoma is not seen in papillary cystadenoma and helps to differentiate.

The most important differential diagnosis of papillary cystadenoma is cystadenocarcinoma as both neoplasms have similar architecture with papillary proliferation of the epithelial lining and are composed of cells that possess bland cytomorphologic features [12]. Moreover, 
cystadenocarcinoma often shows little atypia [13]. Differentiation of tumour types depends largely on the identification of actual infiltration of salivary gland parenchyma or surrounding connective tissue by either cystic or solid epithelium in cystadenocarcinomas.

The suggested management for these benign lesions is conservative and consists of complete local excision $[5,14]$. Open laryngeal surgery like Lateral/Median Thyrotomy and pharyngotomy approach or transoral approach is required for the cartilaginous structures of the larynx; if the position of larynx is to be altered, or if the anatomical situation of lesion prevents adequate endoscopic visualization.

Laryngeal lesions located in the mucosa or sub mucosal space is easily accessible to endoscopic approach with advantages of avoidance of skin incisions, division of the thyroid cartilage and tracheotomy.

The surgical approach and excision depend on the tumor size and location; but in general, preservation of laryngeal function is the primary aim of treatment in the form of complete excision with tumor-free margins. With improvements in imaging, histopathology, and surgical techniques - endoscopy, microscopic magnification, application of lasers - there has been marked improvement in the accuracy of diagnosis and the ability to perform precision excision surgery for benign tumors. This means more preservation and restoration of laryngeal function than was previously possible [15]. As per the recommendations, we completely excised the entire cysts in supraglottis by endoscopic micro laryngeal surgery and histopathology reconfirmed the diagnosis as benign papillary cystadenoma. Although papillary cystadenoma are benign lesions, follow-up is recommended, as recommended for oncocytic cysts since recurrence is possible, especially in the case of patients with multiple involvements, with a tendency to develop new cysts [16]. In our case, considering the benign nature of the lesions, annual revisions were decided for a minimum period of five years.

\section{Conclusion}

We present this case of multiple laryngeal papillary cystadenomas, a rare benign lesion presenting with hoarseness and dysphagia as this clinical entity has to be kept in mind while evaluating patients with above mentioned symptoms. Moreover, the histo-pathological diagnosis is crucial as many tumours are with similar features and management of each varies.

\section{REFERENCES}

[1] P. L. Auclair, G. L. Ellis and D. R. Gnepp, “Other Benign Epithelial Neoplasms,” In: G. L. Ellis, P. L. Auclair and D. R. Gnepp, Eds., Surgical Pathology of the Salivary
Glands, Saunders, Philadelphia, 1991, pp. 252-268.

[2] C. A. Waldron, S. K. El-Mofty and D. R. Gnepp, “Tumors of the Intraoral Minor Salivary Glands: A Demographic and Histologic Study of 426 Cases,” Oral Surgery, Oral Medicine, Oral Pathology, Vol. 66, No. 3, 1988, pp. 323-333.

http://dx.doi.org/10.1016/0030-4220(88)90240-X

[3] J. Alexis, "Dewbrow Papillary Cystadenoma of a Minor Salivary Gland,” Journal of Oral and Maxillofacial Surgery, Vol. 53, No. 1, 1995, pp. 70-72.

http://dx.doi.org/10.1016/0278-2391(95)90506-5

[4] G. Seifert, "Histological Typing of Salivary Gland Tumors,” In: World Health Organization International Histological Classification of Tumors, Springer, Geneva, 1991.

[5] L. Michaels and H. B. Hellquist, "Ear Nose and Throat Histopathology,” 2nd Edition, Springer, Berlin, 2001, p. 489. http://dx.doi.org/10.1007/978-1-4471-0235-9

[6] C. A. Waldron, S. K. El-Mofty and D. R. Gnepp, “Tumors of the Intraoral Minor Salivary Glands: A Demographic and Histologic Study of 426 Cases," Oral Surgery, Vol. 66, No. 3, 1988, pp. 323-333. http://dx.doi.org/10.1016/0030-4220(88)90240-X

[7] A. P. Chaudhry, R. A. Vickers and R. J. Gorlin, "Intraoral Minor Salivary Gland Tumors: An Analysis of 1414 Cases," Oral Surgery, Oral Medicine, Oral Pathology, Vol. 14, No. 10, 1961, pp. 1194-1126. http://dx.doi.org/10.1016/0030-4220(61)90209-2

[8] C. S. Lim, I. Ngu, A. P. Collins and G. M. McKellar, "Papillary Cystadenoma of a Minor Salivary Gland: Report of a Case Involving Cytological Analysis and Review of the Literature," The Online Version of Oral Surgery, Oral Medicine, Oral Pathology, Oral Radiology, and Endodontology, Vol. 105, No. 1, 2008, pp. e28-e33. http://dx.doi.org/10.1016/j.tripleo.2007.07.019

[9] G. L. Ellis and P. L. Auclair, "Atlas of Tumor Pathology: Tumors of the Salivary Glands,” Armed Forces Institute of Pathology, Washington DC, 1995, pp. 115-120.

[10] J. W. Eveson and T. Nago, “Cystadenoma,” In: L. Barnes, Ed., Diseases of the Salivary Glands. Surgical Pathology of the Head and Neck, 3rd Edition, Informa Healthcare, New York, 2009, pp. 538-540.

[11] G. Seifert, C. Brocheriou, A. Cardesa and J. W. Eveson, "WHO International Histologic Classification of Tumours. Tentative Histological Classification of Salivary Gland Tumours," Pathology, Research and Practice, Vol. 186, No. 5, 1990, pp. 555-581.

http://dx.doi.org/10.1016/S0344-0338(11)80220-7

[12] L. Gallego, L. Junquera, M. F. Fresno and J. C. De Vicente, "Papillary Cystadenoma and Cystadenocarcinoma of Salivary Glands: Two Unusual Entities,” Medicina Oral Patologia Oral y Cirugia Bucal, Vol. 13, No. 7, 2008, pp. 460-463.

[13] R. D. Foss, G. L. Ellis and P. L. Auclair, "Salivary Gland Cystadenocarcinomas. A Clinicopathologic Study of 57 Cases," American Journal of Surgical Pathology, Vol. 20, No. 12, 1996, pp. 1440-1447. http://dx.doi.org/10.1097/00000478-199612000-00002

[14] A. N. Kalof, M. F. Evans and K. Cooper, "Special Diag- 
nostic Techniques in Surgical Pathology,” In: P. Gattuso, V. B. Reddy, O. David and D. J. Spitz, Eds., Differential Diagnosis in Surgical Pathology, 2nd Edition, Saunders, Philadelphia, 2010, pp. 156-157.

http://dx.doi.org/10.1016/B978-1-4160-4580-9.00001-0

[15] D. G. Grant, M. A. Birchall and P. J. Bradley, "Surgery for Benign Tumors of the Adult Larynx,” In: M. Remacle and H. E. Eckel, Eds., Surgery of Larynx and Trachea, Springer, Berlin, 2010, pp. 91-111.

[16] J. K. Dhingra, N. M. Aqel, J. McEwen and N. R. Bleach, "Multiple Oncocytic Cysts of the Larynx," The Journal of Laryngology \& Otology, Vol. 109, No. 12, 1995, pp. 12261228. http://dx.doi.org/10.1017/S0022215100132529 